\title{
Does Recreational Computer Use Affect High School Achievement? ${ }^{1}$

\author{
Alex J. Bowers ${ }^{2}$ \& Matthew Berland ${ }^{3}$
} \\ bowers@tc.edu, mberland@wisc.edu
}

\begin{abstract}
Historically, the relationship between student academic achievement and use of computers for fun and video gaming has been described from a multitude of perspectives, from positive, to negative, to neutral. However, recent research has indicated that computer use and video gaming may be positively associated with achievement, yet these studies have focused on small intact and qualitative samples. The purpose of the present study is to examine the association between academic achievement in high school and student use of computers for fun and video gaming using the large nationally representative ELS:2002 sample of students in grade 10 in 2002 and an independent effects two-level hierarchical linear model. Our results indicate that both student use of computers for fun and moderate levels of video gaming were positive and significant on cross-sectional reading and mathematics achievement assessments in high school, controlling for multiple covariates of achievement, but were not related to growth in mathematics from grade 10 to grade 12 .
\end{abstract}

Keywords: Secondary education, high school, computer attitudes, video games, computer based communication, computer access, achievement, reading, mathematics, television, internet, extracurricular activities, homework

\section{LITERATURE REVIEW:}

The prevailing image in the popular media is that frequent users of computers for fun are maladjusted (e.g. Klein, 2010), including students who play video or computer games as well as students who use computers recreationally, such as for email, messaging with friends, reading websites and listening to digital music. Indeed, the APA released a resolution in which they encouraged parents to restrict computer use except for homework (APA, 2005). Evidence suggests, however, that recreational computer use is not the culprit in decreased test scores. Early in the modern PC age, Papert (1980) showed that computers can be "protean tools to think with" - they can be used as raw tools for learning through creating and playing with meaningful content. More recently, Jenkins (2006b) showed how students can make meaningful literacy gains using technology to communicate interests around games and popular media. Gee (2004) showed

\footnotetext{
${ }^{1}$ This manuscript is a preprint of an article published in 2013 in the journal Educational Technology Research \& Development. Recommended citation format:

Bowers, A.J., Berland, M. (2013) Does Recreational Computer Use Affect High School Achievement? Educational Technology Research \& Development, 61(1), 51-69. doi:10.1007/s11423-0129274-1

${ }^{2}$ Teachers College, Columbia University, 525 W. $120^{\text {th }}$ Street, New York, New York 10027.

ORCID: 0000-0002-5140-6428, ResearcherID: C-1557-2013

${ }^{3}$ University of Wisconsin-Madison, School of Education, Department of Curriculum and Instruction

Note: This document was last updated August 12, 2013
}

how video games can be both a source and a platform for learning and literacies. While there is evidence that student video gaming and using computers for fun can be a positive outlet and a communication link to positive academic resources, less is known about the association between this behavior and academic achievement. Thus, the purpose of this study is to examine associations between student achievement in high school, computer use for fun and video gaming, controlling for known covariates of achievement, using a large nationally representative U.S. sample.

Some literature suggests that high school students using computers extensively for fun (such as for games, surfing the internet, communicating with friends, etc.) is, at best, neutral in relationship to school grades and tests, and, at worst, a waste of time and directly harmful to attention, performance, or even morality (e.g., Gentile, Lynch, Ruh Linder, Walsh 2004; Swing, Gentile, Anderson, \& Walsh, 2010). However, much of this work rests on the assumption that student attention is limited and fixed, in that these studies examine the amount of time devoted to gaming or surfing the internet, and use those data to conclude that the use of computers for fun is itself a negative on academic achievement. In addition, much of this research does not control for the set of variables that are understood to covary with achievement, technology access, and technology use, such as socio-economic status (SES). However, student attention and motivation often synergize with recreational computer use, leading to increased student achievement (Sutherland, Facer, Furlong, \& Furlong, 2000).

\section{The Relationship of Computer Use to Student Achievement}

Recent work suggests that searching for information online, online social networking and being involved in online communities may be positively related to student learning (Brand-Gruwel, Wopereis, \& Vermetten, 2005; Jonassen \& Kwon, 2001; Tabatabai \& Shore, 2005), especially at the high school level. For instance, Steinkuehler and Duncan (2008) show how students engaged in message boards can communicate and reason scientifically at a higher grade level than would be evidenced by their school performance, and that they can bring those literacy skills back to school. Forte and Bruckman (2006) show that students working on Wikipedia have access to a variety of unique learning experiences. However, the biggest benefits of online communities appear to come from identity formation and physical community reinforcement. Lewis and Fabos (2005) show that students often do relatively difficult and involved identity formation work in online chats, and that the added convenience reinforces existing real-world friendships. This builds upon foundational work by Turkle (1995) in which she showed how online chatting and communities serve as sites for young users to create new identities and find a meaningful sense of self. More recent research by boyd (2008) shows how social networks and public communities can be systematically positive experiences for students. 
The Relationship of Videogaming to Student Academic Achievement

Recent research repeatedly suggests that moderate use of video games can have myriad benefits for thinking and learning. At one extreme, McGonigal (2011) suggests that video games are fundamentally reshaping humanity for the better: that we are learning how to achieve goals, are rewarded for hard work, and find real value in substantive communication. Gee (2004) and Collins and Halverson (2009) suggest that games and social media can employ a more coherent theory of learning than traditional education does. Gee posits that a fun game may contain an implicit theory of learning more well-suited to complex content than school does. Games can foster complex literacies and reinforce cognitive work that grapples with complex content.

Indeed, students can otherwise use skills gained by playing computer games, such as visual attention (Green \& Bavelier, 2003), to improve educational outcomes. As shown by Harel and Papert (1980), sometimes "more is less." They propose an "integrated learning principle" that suggests that gaining multiple deep understandings in a motivating way is often much easier for students than learning disconnected simple facts or surface-level understandings. This corresponds to work by Wilensky (1993) showing that understanding is often in the form of "connections" to content - rather than simply time on task - and these connections are more reliable predictors of transferable understanding. Berland and Lee (2011) suggest that students playing games may be learning to articulate complex logic. Together, this work shows that there is no simple equation for the relationship between student activity and student learning. Gee (2004) shows how students engaged in commercial video games are actively engaged in mathematics, reading, and science, and that they intentionally and independently pursue more difficult reasoning problems in the space of the game. Subrahmanyam, Greenfield, Kraut, and Gross (2001) show that general computer use by teens can have myriad positive social, cognitive, and academic implications for teenagers. Indeed, Papert (1980) suggests that spending time having "hard fun" on computers can be more productive than simply studying or doing homework. Our work in the present study suggests that these phenomena may be happening at a larger scale than previously understood. However, research on the evidence of estimates of positive effects of videogaming and computer use for fun demonstrates conflicting results.

Vigorous debates continue in the recent research literature around work on violence and aggression correlated with youth who play violent video games (Anderson et al., 2010; Ferguson \& Kilburn, 2010; Huesmann, 2010). In a meta-analysis of the correlates of youth aggression, violence, and violent videogame playing, Anderson et al. (2010) showed small but consistent effects across multiple studies which suggest that students feel aggressive while playing violent video games. However, Ferguson and Kilburn (2010) dispute any broader implication of the findings, critiquing the meta-analytic methods of Anderson et al. (2010) such as the inclusion of many unpublished studies in the meta-analysis, that effect size estimates were upwardly biased, and the cited literature did not control for known covariates. Nevertheless, while the debate over a link between violent video games and youth aggressive behavior continues, what is left unaddressed in the Anderson et al. (2010) meta-analysis and resulting critiques is that little work has been done to date that examines the association between academic achievement, videogaming (violent or otherwise), and computer use among students. Of the few studies that have been done, results are conflicted due to methodological issues, as well as the problem of examining how students are using computing technology and how this technology may or may not contribute to their academic achievement in school.

As an example from this prior literature on videogaming and student achievement, Gentile et al. (2004) showed that with a sample of 502 grade 8 and 9 students from the U.S. Midwest, violent videogaming was significantly negatively related to selfreported grades, but the research was methodologically problematic. In addition to the small non-random sample in Gentile et al. (2004) and known validity issues with student selfreported grades (Kuncel, Crede, \& Thomas, 2005) as well as how grades are not a pure measure of academic achievement (Bowers, 2009, 2011), more problematic was that the authors of the study did not control for the multiple known covariates of student achievement, such as SES, as well as student access to technology. Indeed, past research has demonstrated that family socio-economic status is strongly related to not only student academic achievement, but also student access and use of technology (Jackson, 2008; Pew, 2000, 2005, 2006).

For much of the past research examining the influence of access to computers and technology on academic achievement, studies have found conflicting evidence. Malamud and Pop-Eleches (2008) found that computer use at home had a negative effect on student achievement in Romania, but they did not effectively control for covariates of achievement and their target population in Romania was markedly different from the U.S. context. Fuchs and Woessmann (2007) found that in examining PISA 2000 data from 15-year olds across 32 developed and developing countries, simply owning a computer at home was negatively correlated with student achievement in mathematics and science once the covariates of achievement were controlled for. However, in an earlier study, Fuchs and Woessmann (2004) found a positive relationship between student home internet use and student achievement, indicating that student "computer use" may be more complex than just owning a computer, and may relate more to how the student interacts with the technology in different ways.

Multiple studies have demonstrated a positive relationship between access to computers at home and student achievement. Attewell and Battle (1999) demonstrated a positive relationship using the nationally generalizable NELS:88 sample of 18,000 U.S. eighth grade students in 1988, showing positive relationships across reading, mathematics, and grades to student access to a computer at home, when controlling for a host of covariates, including SES. This result has been replicated in more recent samples across additional contexts by the OECD (2006), and with Norwegian students (Nævdal, 2007). In addition, in contrast to Fuchs and Woessmann (2007), Papanastasiou (2003) demonstrated that when they focused on the U.S. sample from the PISA 2000 dataset, access to computers at home was a positive predictor of student academic achievement.

Toward a Broader Framework for Studying Computer and Technology Use

Consequently, the research in this domain of the relationship of computer use and videogaming to student academic achievement presents a set of conflicting studies and effects. However, studies 
by Willoughby (2008), Jackson et al. (2011), and Wittwer and Senkbeil (2008) help frame a broader theory of computer use that can then be tested using large nationally generalizable samples while controlling for both appropriate covariates of academic achievement and access to computers and videogames.

Recently, multiple studies have demonstrated a difference in effects on student achievement between recreational computer use "for fun" and videogaming. Willoughby (2008) surveyed 1,591 Ontario Canadian students to examine the relationship between internet use, computer gaming, and "academic orientation" as measured through self-reported grades, educational aspirations, and student self-perceptions of doing 'well' in school. The author found significant and positive relationships between internet use, computer gaming, and academic orientation. Jackson et al. (2006), in a similar study of 140 low SES students between the ages of 10 and 15 in the U.S. showed a positive relationship between internet use and standardized reading scores, but showed that there was no relationship between internet use and mathematics scores. Following this previous work, Jackson, von Eye, Witt, Zhao, and Fitzgerald (2011) examined the effects of internet use and videogaming on student academic achievement. Their sample consisted of 482 middle school students from across 20 Michigan schools. They found that internet use was positive and significant on reading achievement, videogame use was negative and significant on self-reported GPA, and internet use and videogame use were unrelated to mathematics and visual space skills, while controlling for student gender, family SES and ethnicity. Together, these studies demonstrate initial evidence for a more complex model of how students interface with computers, and how different types of student computer use may differentially influence academic achievement. However, all of these studies suffer from many of the same methodological issues as above, such as small intact non-random samples and a failure to control for the breadth of known covariates of not only technology access but student achievement in general.

In contrast to the above studies, in one of the most comprehensive studies to date in this domain, Wittwer and Senkbiel (2008) examined the PISA 2003 sample of 4,660 15-year old German students, in which they postulated a model of student engagement with computers and videogames that demonstrated the difference between the relationship of recreational computer use and video gaming on academic achievement. First, Wittwer and Senkbiel (2008) examined the relationship between having a computer in the home, frequency of computer use and mathematics achievement, showing significant and positive relationships. However, when they controlled for multiple covariates of achievement, these broad measures of computer access and use were no longer significantly related to achievement. Interestingly however, they then conducted a latent class analysis to examine a typology of student computer use, finding multiple types of computer users. The authors demonstrated a significant positive relationship between mathematics achievement and students who were "smart" computer users who used computers for communicating online, viewing videos and pictures, and gaming, who also reported that they acquired their computer skills on their own. This was in comparison to students who used computers mainly for school and communicating online, for gaming, or for neither, each of which were not related to student achievement. In summarizing their study as it relates to the broader discussion of the relationship of computer use to achievement, Wittwer and Senkbeil (2008) noted that:

Bowers \& Berland (2013) Computer Use and Student Achievement
In exploring the potential of using a home computer for students' academic achievement, it seems to be crucial to delve more deeply into the way students use a computer at home instead of mainly investigating whether, or how often, a computer is used. (p.1570)

Thus, although Wittwer and Senkbeil's (2008) findings are focused on German students, their results, in combination with the other studies discussed above on student internet use and gaming, suggest a broader theory of student computer use and its influence on achievement. This research presents a set of findings that indicate that using a computer for fun, such as using the internet, communicating with friends, watching videos and listening to music, may be positively related to both reading and mathematics while videogaming appears to be either unrelated to academic achievement or negative. However, due to the different national contexts and varying sample sizes and non-randomness across the studies, it is difficult to generalize. However, these studies point to the issue that computer use may influence student achievement.

\section{Framework of the Study:}

Thus, overall the research to date indicates that not only do students use computers in different ways, but that these different uses relate to academic achievement differently. However, the majority of the findings to date have depended on small nonrandom samples, or contexts outside of the U.S., and have not consistently controlled for the multiple known covariates of student achievement. The purpose of this study is to examine the extent of the association between multiple forms of student computer use "for fun" and academic achievement to help inform a broader theory of how recreational computer use may or may not influence achievement in high school. Given the findings in the research detailed above, we build upon the findings from Jackson et al. (2011) and Wittwer and Senkbeil (2008) and separate student recreational computer use into two categories: 1) computer use "for fun" which includes browsing the internet, communicating with friends and listening to music; 2) and videogaming. As such, the research questions for this study are:

1) To what extent is using computers for fun and video gaming associated with academic achievement in grades 10 and 12, controlling for other known covariates of academic achievement, using a large nationally representative sample?

2) Is the association with using computers for fun and video gaming negative, neutral or positive on student achievement when examining an independent effects model?

\section{METHODS}

\section{Sample}

This study was a secondary analysis of the Education Longitudinal Study of 2002 (ELS:2002) restricted-access data. ELS:2002 was originally collected by the National Center for Education Statistics (NCES) in 2002 (Ingles et al., 2004; Ingles et al., 2007; NCES, n.d.) which surveyed about 15,400 students who were in grade 10 in 2002 across about 750 high schools in the United States and then resurveyed the students in 2004. The NCES survey included a variety of questions pertaining to student attitudes, background and demographics, and NCES tested the students on standardized measures of reading and mathematics in 
Table 1: Descriptives for variables included in the model

\begin{tabular}{|c|c|c|c|c|c|}
\hline Variables & Mean & $(S D)$ & Min & $\operatorname{Max}$ & ELS:2002 variable label and description \\
\hline \multicolumn{6}{|l|}{ Student recreational tech use } \\
\hline How often uses computer for fun & 3.04 & $(1.24)$ & 0 & 4 & $\begin{array}{l}\text { BYS45A: How often uses computer for fun. } 0=\text { never, } \\
1=\text { rarely, } 2=\text { less than once a week, } 3=\text { once or twice a week, } \\
4=\text { everyday or almost everyday }\end{array}$ \\
\hline Video games 1-2 hrs per day & 0.47 & $(0.50)$ & 0 & 1 & $\begin{array}{l}\text { BYS49A \& BYS49B: Plays video or computer games one or } \\
\text { two hours per day either weekdays or weekends }\end{array}$ \\
\hline \multicolumn{6}{|l|}{ Student Background } \\
\hline Female & 0.50 & $(0.50)$ & 0 & 1 & BYSEX = 1 \\
\hline African American & 0.17 & $(0.37)$ & 0 & 1 & BYRACE $2=1$ \\
\hline Asian & 0.12 & $(0.33)$ & 0 & 1 & BYRACE3 = 1 \\
\hline Hawaiian/Pacific Islander & 0.02 & $(0.14)$ & 0 & 1 & BYRACE4 = 1 \\
\hline Native American & 0.04 & $(0.21)$ & 0 & 1 & BYRACE5 = 1 \\
\hline Hispanic & 0.09 & $(0.28)$ & 0 & 1 & BYS15 = 1 \\
\hline English is first language & 0.86 & $(0.35)$ & 0 & 1 & BYSTLANG = 1 \\
\hline Non-Traditional family & 0.40 & $(0.49)$ & 0 & 1 & BYFCOMP > 1: Both birth parents not present in home \\
\hline SES & 0.07 & $(0.73)$ & -2.12 & 1.81 & F1SESR: Socio-economic status \\
\hline \multicolumn{6}{|l|}{ Hrs/wk spent on: } \\
\hline Homework in school & 4.78 & $(4.94)$ & 0 & 21 & BYS34A \\
\hline Homework out of school & 6.15 & $(5.90)$ & 0 & 26 & BYS34B \\
\hline Extracurricular activities & 4.94 & $(5.67)$ & 0 & 21 & BYS42 \\
\hline Reading outside of school & 2.78 & $(3.81)$ & 0 & 21 & BYS43 \\
\hline \multicolumn{6}{|l|}{ Hrs/day spent watching: } \\
\hline TV on weekdays & 2.94 & $(1.94)$ & 0 & 6 & BYS48A \\
\hline TV on weekends & 3.97 & $(1.83)$ & 0 & 6 & BYS48B \\
\hline \multicolumn{6}{|l|}{ Subject attitude } \\
\hline Reads in spare time & 1.48 & $(0.88)$ & 0 & 3 & $\begin{array}{l}\text { BYS87D: } 0=\text { strongly } \quad \text { disagree, } 1=\text { disagree, } 2=\text { agree, } \\
3=\text { strongly agree }\end{array}$ \\
\hline Mathematics is important & 1.49 & $(0.85)$ & 0 & 3 & $\begin{array}{l}\text { BYS87F: } 0=\text { strongly disagree, } 1=\text { disagree, } 2=\text { agree, } \\
3=\text { strongly agree }\end{array}$ \\
\hline \multicolumn{6}{|l|}{ Family computer use } \\
\hline Family has a computer & 0.87 & $(0.30)$ & 0 & 1 & $\mathrm{BYS} 84 \mathrm{C}=1$ \\
\hline Parents limit TV \& video games & 1.19 & $(1.02)$ & 0 & 3 & BYS85F: $0=$ never, $1=$ rarely, $2=$ sometimes, $3=$ often \\
\hline \multicolumn{6}{|l|}{ Standardized Test Scores } \\
\hline Grade 10 Reading & 50.98 & $(9.91)$ & 22.57 & 78.76 & BYTXRSTD: Grade 10 reading stand. T-score \\
\hline Grade 10 Mathematics & 51.14 & $(9.92)$ & 19.38 & 86.68 & BYTXMSTD: Grade 10 mathematics stand. T-score \\
\hline Grade 12 Mathematics & 50.33 & $(10.18)$ & 19.64 & 80.39 & F1TXMSTD: Grade 12 mathematics stand. T-score \\
\hline$n$ & 13,960 & & & & \\
\hline
\end{tabular}

grade 10 and mathematics in grade 12 . Our sample consisted of all students with complete data on demographic and background variables, $n=13,960$ across 750 high schools. Due to data confidentiality issues, sample sizes have been rounded to the nearest ten.

\section{Variables included in the analysis}

We used the past literature and theory to help guide our selection of variables for this study. Descriptives for the variables included in the analysis discussed below are presented in Table 1, including the mean, standard deviation, minimum, maximum and ELS:2002 variable label and coding. The dependent variables in the models were standardized assessments of grade 10 reading, grade 10 mathematics and grade 12 mathematics. Unfortunately, NCES did not test reading in grade 12 so we were unable to include it. Variables in the analysis that were used as controls on achievement were included based on the past literature that has indicated that either a) the variable is related to student achievement in U.S. schools (Archibald, 2006; Rumberger \&
Palardy, 2005) or b) the variable has been nominated in the gaming and technology literature as related to student achievement (Southwell \& Doyle, 2004; Attewell \& Battle, 1999; Jackson et al., 2011; Wittwer \& Senkbeil, 2008). These variables included five different types of variables. First, student background variables included if a student was Female with male as the reference group, and African American, Asian, Hawaiian/Pacific Islander, Native American, or Hispanic, with European American as the reference group. Additional background variables included if English is the first language for the student, if the student comes from a Non-Traditional Family, and the Socio-economic status (SES) of the student's family. Second, to control for the amount of time devoted to schoolrelated tasks (Borzekowski \& Robinson, 2005), we included hours per week that the student spends on Homework in school, Homework out of school, Extracurricular activities, and Reading outside of school. Third, to control for the well-known negative effects of time devoted to watching television on academic achievement (Borzekowski \& Robinson, 2005; Hancox, Milne, \& Poulton, 2005; Keith, Reimers, Fehrmann, Pottebaum, \& Aubey, 
1986), we included the variables hours per day spent watching $T V$ on weekdays and $T V$ on weekends. Fourth, we included two variables related to the student's attitude towards reading and mathematics in which NCES asked the student if they Read in their spare time, and think that Mathematics is important. Fifth, to control for a student's access at home to technology we included the control variables Family has a computer and Parents limit TV and video games.

To examine student recreational use of computers for fun and video gaming we included the following two variables. First, to capture student recreational computer usage that corresponds with the types of "for fun" activities reviewed above, such as internet use and communicating with friends, we included the variable BYS45A, in which NCES asked the students the following question: "Whether at home, school, or someplace else, how often do you use a computer for fun, such as talking to friends or relatives through E-mail, playing games, surfing the internet, or listening to music?". We termed this item as How often student uses computer for fun. Second, to capture an indication of the amount of time devoted to video and computer gaming, we used the NCES variables BYS49A and BYS49B in which NCES asked the students "during the school year, how many hours a day do you usually play video or computer games such as Nintendo or PlayStation" on weekdays (BYS49A) or weekends (BYS49B). Answers ranged from zero to 6 or more hours. However, for students who indicated some amount of time devoted to gaming, these variables were multi-modal, with males having peaks at one and six hours for both weekdays and weekends, while females had a positively skewed distribution with a peak at one hour. For both females and males the distributions decreased substantially after one and two hours. In addition, the literature indicates that high amounts of time devoted to gaming decreases time devoted to sleep as well as other school-related activities (Van den Bulck, 2004). Due to these distributional and construct issues we created a single "moderate gamer" variable that included students who reported playing video or computer games by BYS49A or BYS49B one to two hours either on weekdays or weekends. We termed this variable Video games 1-2 hrs per day.

\section{Analysis}

To examine the independent effects of using computers for fun and video gaming on student achievement in high school, we used a set of fixed effects two-level hierarchical linear models (HLM) with students at level 1 nested in schools at level 2 in which the dependent variables were student grade 10 reading, grade 10 mathematics, or grade 12 mathematics. HLM was an attractive analysis technique because it appropriately controls for the dependent nature of students nested in schools and decomposes the variance in achievement between the student and school levels (Hox, 2010; Raudenbush \& Bryk, 2002). In this study, we focus on isolating the independent student-level effects of recreational computer use on achievement, and since there is no theory or literature to date that indicates that either students using computers for fun or video gaming varies systematically across schools, our models include the known covariates of student achievement at the student-level with no predictors at the school level. As such, our models can be represented in general using the nomenclature of Raudenbush and Bryk (2002) with the equation:
Level 1: $Y_{i j}=\pi_{0 j}+\pi_{1 j} X_{i j} \ldots+e_{i j}$

Equation (1)

Level 2:

$$
\pi_{0 j}=\gamma_{00}+r_{0 j}
$$$$
\pi_{1 j}=\gamma_{01}
$$

Equation (2)

In which:

$Y_{i j}=$ Dependent outcome variable for student $\mathrm{i}$ in school $\mathrm{j}$; grade

10 reading, mathematics or grade 12 mathematics.

$X_{i j}=$ Student level covariates

$\pi_{0 j}=$ The slope of the intercepts varying across schools

$\pi_{1 j}=$ The slope of each covariate across schools

For all models, we used HLM 7.0 (Raudenbush, Bryk, Cheong, Congdon, \& duToit, 2011) and report parameter estimates with robust standard errors. As a fixed effects model, only the intercept is allowed to vary randomly across the schools. However, HLM allows for this constraint to be relaxed, and so we examined the models under relaxed conditions in which the predictors were allowed to vary as a function across schools. We found few significant effects, and none that substantively changed the parameter estimates. Thus we report only the fixed effects models. Across the variables included in the analysis, there was $17 \%$ or less missing data, except for reads in spare time $(28 \%$ missing), mathematics is important (27\% missing) and parents limit TV and video games ( $20 \%$ missing). To include these variables we used multiple imputation in SPSS 19 (SPSS, 2010) with a Markov chain Monte Carlo (MCMC) fully conditional specification as recommended with this type of data (Graham, Cumsille, \& Elvira, 2003), with ten imputations and categorical variables included only as predictors. Additionally, as the NCES collected the data using a complex probabilistic sampling procedure that allows generalization to all 3.4 million US $10^{\text {th }}$ graders in 2002, we applied the normalized student expanded sample weight (BYEXPWT) at the student level and the schoollevel weight (BYSCHWT) at the school level for all models as recommended for these types of data (Ingles, et al., 2004; Strayhorn, 2009). Because normalized weights were applied, sample sizes are unchanged by the weighting procedure.

\section{RESULTS}

In this section, we describe the relationship of students' selfreports of how often they use computers for fun and video gaming to academic achievement in high school. As noted above, given the conflicting literature on the effects of recreational computer use by students on achievement, the focus of this study was to determine if using computers for fun and video gaming was positive, negative or neutral using a large representative sample of U.S. high school students. First, we examine the correlations between recreational computer use and student achievement, and then we present four two-level hierarchical linear models to examine the relationship between using computers for fun, video gaming, and academic achievement while controlling for covariates of student achievement. We then turn to a discussion of our findings. 
Table 2: Correlation coefficients comparing student recreational computer use variables and achievement.

\begin{tabular}{|c|c|c|c|c|}
\hline & $\begin{array}{l}\text { How often uses } \\
\text { computer for fun }\end{array}$ & $\begin{array}{c}\text { Video games 1-2 } \\
\text { hrs per day }\end{array}$ & Grade 10 Reading & $\begin{array}{c}\text { Grade } 10 \\
\text { Mathematics }\end{array}$ \\
\hline How often uses computer for fun & -- & & & \\
\hline Video games 1-2 hrs per day & $0.094 * * *$ & -- & & \\
\hline Grade 10 Reading & $0.250 * * *$ & $0.055 * * *$ & -- & \\
\hline Grade 10 Mathematics & $0.266 * * *$ & $0.087 * * *$ & $0.738 * * *$ & -- \\
\hline Grade 12 Mathematics & $0.268 * * *$ & $0.096 * * *$ & $0.711 * * *$ & $0.889 * * *$ \\
\hline
\end{tabular}

Note: $* * * p<0.001$.

Table 2 presents the Pearson correlations for how often students use computers for fun and video gaming 1-2 hours per day with grade 10 reading, mathematics and grade 12 mathematics. The correlations presented in Table 2 indicate that all of the relationships are positive and significant. How often students use computers for fun has a low to moderate correlation at about 0.25 across reading and mathematics, while video gaming 1-2 hours per day, while positive and significant, was correlated at a very low level, with each correlation below 0.1. Interestingly, the correlation between the variables how often student uses computer for fun and video gaming 1-2 hours per day was positive and significant, but low at 0.094. Thus, while the question "how often do you use a computer for fun" did include gaming as part of the definition for "fun" (see methods) we argue that these two variables represent different constructs, with computers for fun including gaming to some extent but more importantly also including early forms of social networking and online communication in 2002 as well as surfing the internet and listening to digital music. This point is exemplified when we examine the students who reported zero hours gaming per day on either weekdays or weekends, which included $34.1 \%$ of the sample. When these same "non-gamer" students were asked how often they use a computer for fun, they reported a mean of 2.88 with a standard deviation of 1.34 , indicating that on average they used a computer for fun about once or twice a week, which is slightly lower than the sample mean of 3.04. Nevertheless, in addressing the question from the literature of if using computers for fun or video gaming is positive, negative, or neutral, the results from Table 2 indicate that recreational computer use by students likely has a positive relationship. We turn next to examining these relationships while controlling for known covariates of academic achievement.

Table 3 and Table 4 present the results of the two-level HLMs. We analyzed four models, each with a different standardized academic achievement assessment as the dependent variable; reading grade 10 (Table 3: Model $A$ ), mathematics grade 10 (Table 3: Model B), mathematics grade 12 (Table 4: Model C), growth in mathematics grade 12 (Table 4: Model D). Each of the four models includes the two variables how often uses computer for fun and video games 1-2 hours per day, and controls for the five different types of variables detailed in the methods, including student background, hours per day spent on school related activities, hours per day spent watching television, subject attitudinal variables, and family computer use. Model D in Table 4 includes the additional prior achievement variable grade 10 mathematics, focusing the model on estimating the parameters on growth in achievement in mathematics from grade 10 to grade 12, or in other words, testing for a change in effect beyond that included within the grade 10 scores. In all models, continuous variables are grand mean centered, and specific variables as noted in the tables are square root transformed.
Overall, in examining the interclass correlation coefficients, about three quarters of the variance in student achievement was at the student level across the four models. Models A, B and C explained about $18 \%$ to $20 \%$ of the variance at the student level in cross-sectional grade 10 reading, mathematics and grade 12 mathematics, respectively (Table $3 \& 4$, bottom section). Model $\mathrm{D}$ explained about $75 \%$ of the variance at the student level, mostly due to the inclusion of prior grade 10 mathematics performance. We ran each of the models without the student technology use variables and then compared them with the final models to examine the amount of additional variance explained by the variables how often uses computer for fun and video games 1-2 hours per day (Table $3 \& 4$, bottom row). For grade 10 reading, student recreational computer use explained an additional $0.604 \%$ of the variance, while the grade 10 mathematics and grade 12 mathematics variables explained an additional $1 \%$ of the variance. For growth in grade 12 mathematics achievement, the student recreational computer use variables were not significant.

In examining the parameter estimates in each of the models, as the primary finding of this study, our findings indicate that how often a student uses computers for fun and video gaming 1-2 hours per day are significant and positively related to initial status in high school reading and mathematics in grade 10 and 12, but do not appear to contribute beyond this effect accumulated by grade 10 during the time between grades 10 and 12 in mathematics (e.g. the growth model). In other words, the findings from the Model D growth model suggest that these two variables influence student achievement similarly in grade 10 and grade 12; there is no significant difference in effect size. In examining the included covariates in each of the models, this study replicates and extends much of the past research on the factors most associated with student achievement. Gender was not significantly related to reading achievement, but was negative and significant on mathematics. Other significant negative background predictors included African American, Hispanic, and Non-Traditional family while positive background variables included Asian, English as a first language, and SES. Hours per week spent on homework outside of school and extracurricular activities were both positive and significant on achievement, with reading outside of school positive and significant on reading performance. Interestingly, homework in school was not significant in the models, perhaps providing evidence for a nuanced effect of homework when used either as a way to scaffold study habits outside of school in comparison to replacing instructional time with in-school homework. Time devoted to watching television on weekdays was significantly negatively associated with achievement. With students on average reporting in the sample almost three hours of television viewing on weekdays, we posit that this association mostly represents the zero-sum effect of time, in that as students spend more time 
Table 3: Student-Level Hierarchical Linear Model Estimating Grade 10 Reading and Mathematics

\begin{tabular}{|c|c|c|c|c|c|c|}
\hline \multirow[b]{2}{*}{ Variables } & \multicolumn{3}{|c|}{$\begin{array}{c}\text { Model A } \\
\text { Reading Grade } 10\end{array}$} & \multicolumn{3}{|c|}{$\begin{array}{c}\text { Model B } \\
\text { Mathematics Grade } 10\end{array}$} \\
\hline & Coeff. & $\beta$ & $S E$ & Coeff. & $\beta$ & $S E$ \\
\hline \multicolumn{7}{|l|}{ Student recreational tech use } \\
\hline How often uses computer for fun & $0.518 * * *$ & 0.065 & 0.132 & $0.619 * * *$ & 0.077 & 0.117 \\
\hline Video games 1-2 hrs per day & $0.666^{* *}$ & 0.034 & 0.244 & $1.004 * * *$ & 0.051 & 0.221 \\
\hline \multicolumn{7}{|l|}{ Student background } \\
\hline Female & 0.422 & & 0.306 & $-1.883 * * *$ & -0.095 & 0.281 \\
\hline African American & $-4.233 * * *$ & -0.158 & 0.434 & $-5.269 * * *$ & -0.197 & 0.427 \\
\hline Asian & -0.099 & & 0.614 & $1.330^{*}$ & 0.044 & 0.593 \\
\hline Hawaiian/Pacific Islander & -0.370 & & 0.827 & -1.701 & & 1.045 \\
\hline Native American & -0.862 & & 0.582 & -1.270 & & 0.673 \\
\hline Hispanic & $-2.432 * * *$ & -0.069 & 0.467 & $-2.994 * * *$ & -0.085 & 0.566 \\
\hline English is first language & $3.733^{* * *}$ & 0.132 & 0.484 & $2.793 * * *$ & 0.099 & 0.482 \\
\hline Non-Traditional family & $-0.879 * * *$ & -0.043 & 0.263 & $-0.776 * *$ & -0.038 & 0.251 \\
\hline SES & $2.898 * * *$ & 0.213 & 0.222 & $3.000 * * *$ & 0.221 & 0.197 \\
\hline \multicolumn{7}{|l|}{ Hrs/wk spent on: } \\
\hline Homework in school $^{\mathrm{a}}$ & -0.156 & & 0.134 & 0.183 & & 0.125 \\
\hline Homework out of school ${ }^{\mathrm{a}}$ & $0.627 * * *$ & 0.075 & 0.125 & $0.614 * * *$ & 0.074 & 0.133 \\
\hline Extracurr. activities $^{\mathrm{a}}$ & $0.360 * * *$ & 0.053 & 0.093 & $0.562 * * *$ & 0.083 & 0.083 \\
\hline Reading outside of school ${ }^{\mathrm{a}}$ & $0.823^{* * *}$ & 0.088 & 0.147 & 0.204 & & 0.144 \\
\hline \multicolumn{7}{|l|}{ Hrs/day spent watching: } \\
\hline TV on weekdays ${ }^{\mathrm{a}}$ & $-1.282 * * *$ & -0.089 & 0.217 & $-1.147 * * *$ & -0.080 & 0.179 \\
\hline TV on weekends ${ }^{\mathrm{a}}$ & $0.555^{*}$ & 0.033 & 0.243 & 0.378 & & 0.228 \\
\hline \multicolumn{7}{|l|}{ Subject attitude } \\
\hline Reads in spare time & $1.518^{* * *}$ & 0.133 & 0.199 & $0.497 *$ & 0.044 & 0.192 \\
\hline Mathematics is important & $-0.037^{*}$ & -0.003 & 0.149 & $1.227 * * *$ & 0.105 & 0.136 \\
\hline \multicolumn{7}{|l|}{ Family computer use } \\
\hline Family has a computer & $1.639 * * *$ & 0.050 & 0.436 & $1.835 * * *$ & 0.055 & 0.522 \\
\hline Parents limit TV \& video games & -0.051 & & 0.139 & -0.202 & & 0.133 \\
\hline Intercept & $49.906^{* * *}$ & & 0.734 & $48.005 * * *$ & & 0.741 \\
\hline \multicolumn{7}{|l|}{$\%$ of variance } \\
\hline at student level & 77.472 & & & 77.134 & & \\
\hline explained at student level & 18.342 & & & 18.748 & & \\
\hline explained by comp fun and gaming & 0.604 & & & 1.066 & & \\
\hline
\end{tabular}

Note: $* p<0.05, * * p<0.01, * * * p<0.001$. Robust standard errors are reported.

Note: ${ }^{a}$ indicates variable is square root transformed.

Note: All continuous variables are grand mean centered.

Note: Models are weighted with normalized panel weights to adjust the estimates for the complex sampling procedure.

Note: The standardized beta coefficients can be interpreted as effect sizes.

during a weekday watching television, less time is left for studying and sleep. Oddly, there existed a positive (but marginally significant) association between television on weekends and grade 10 reading achievement. This is an interesting result as there is minimal prior quantitative work that connects watching television and growth in academic achievement, though qualitative work may theoretically support it (Jenkins, 2006). Our findings on the subject attitude and family computer use variables replicate and extend the past research to a large nationally representative sample demonstrating the positive effects of students reading in their spare time on reading achievement, and the positive effects of positive attitude towards mathematics on mathematics achievement and family has a computer.

Bowers \& Berland (2013) Computer Use and Student Achievement
In all four models, the standardized beta coefficients can be interpreted as effect sizes, and, as such, they can help contextualize the size of the positive effects of student recreational technology use on cross-sectional achievement in reading and mathematics. Across models A, B and C, the effect size of how often student uses computers for fun ranged from 0.065 to 0.077 while video gaming 1-2 hours per day ranged from 0.034 to a high of 0.051 . For both uses computers for fun and video gaming 1-2 hours per day, the effect sizes, while small, are of comparable size to the positive association between academic achievement and hours per week spent doing homework outside of school, extracurricular activities and reading outside of school (see Tables $3 \& 4$, beta columns). 
Table 4: Student-Level Hierarchical Linear Model Estimating Grade 12 Mathematics

\begin{tabular}{|c|c|c|c|c|c|c|c|}
\hline \multirow[b]{2}{*}{ Variables } & \multicolumn{3}{|c|}{$\begin{array}{c}\text { Model C } \\
\text { Mathematics Grade } 12\end{array}$} & \multicolumn{4}{|c|}{$\begin{array}{c}\text { Model D } \\
\text { Growth Mathematics Grade } 12\end{array}$} \\
\hline & Coeff. & $\beta$ & $S E$ & Coeff. & & $\beta$ & $S E$ \\
\hline \multicolumn{8}{|l|}{ Student computer use for fun } \\
\hline How often uses computer for fun & $0.606 * * *$ & 0.074 & 0.121 & 0.080 & & & 0.068 \\
\hline Video games $1-2$ hrs a day & $0.990 * * *$ & 0.049 & 0.232 & 0.136 & & & 0.155 \\
\hline \multicolumn{8}{|l|}{ Student Background } \\
\hline Female & $-1.592 * * *$ & -0.078 & 0.288 & -0.557 & $* * *$ & -0.027 & 0.158 \\
\hline African American & $-4.988 * * *$ & -0.181 & 0.418 & -0.565 & $* *$ & -0.021 & 0.182 \\
\hline Asian & $1.834 * *$ & 0.059 & 0.623 & 0.796 & $* *$ & 0.026 & 0.279 \\
\hline Hawaiian/Pacific Islander & -1.785 & & 1.008 & -0.344 & & & 0.593 \\
\hline Native American & -0.707 & & 0.615 & 0.326 & & & 0.320 \\
\hline Hispanic & $-2.276^{* * *}$ & -0.063 & 0.502 & 0.282 & & & 0.309 \\
\hline English is first language & $2.748 * * *$ & 0.094 & 0.524 & 0.444 & & & 0.281 \\
\hline Non-Traditional family & $-0.883^{* * *}$ & -0.042 & 0.264 & -0.230 & & & 0.164 \\
\hline SES & $3.315 * * *$ & 0.238 & 0.192 & 0.871 & $* * *$ & 0.062 & 0.105 \\
\hline \multicolumn{8}{|l|}{ Hrs/wk spent on: } \\
\hline Homework in school $^{\mathrm{a}}$ & 0.098 & & 0.123 & -0.058 & & & 0.067 \\
\hline Homework out of school ${ }^{\mathrm{a}}$ & $0.813 * * *$ & 0.095 & 0.122 & 0.331 & $* * *$ & 0.039 & 0.061 \\
\hline Extracurricular activities $^{\mathrm{a}}$ & $0.469 * * *$ & 0.067 & 0.084 & 0.002 & & & 0.047 \\
\hline Reading outside of school ${ }^{\mathrm{a}}$ & $0.345^{*}$ & 0.036 & 0.158 & 0.170 & * & 0.018 & 0.082 \\
\hline \multicolumn{8}{|l|}{ Hrs/day spent watching: } \\
\hline TV on weekdays ${ }^{\mathrm{a}}$ & $-1.221 * * *$ & -0.083 & 0.194 & -0.259 & $*$ & -0.018 & 0.118 \\
\hline TV on weekends ${ }^{\mathrm{a}}$ & 0.278 & & 0.243 & -0.069 & & & 0.138 \\
\hline \multicolumn{8}{|l|}{ Subject attitude } \\
\hline Reads in spare time & $0.549 * *$ & 0.047 & 0.200 & 0.123 & & & 0.099 \\
\hline Mathematics is important & $1.462 * * *$ & 0.122 & 0.149 & 0.427 & $* * *$ & 0.036 & 0.092 \\
\hline \multicolumn{8}{|l|}{ Family computer use } \\
\hline Family has a computer & $1.991 * * *$ & 0.059 & 0.518 & 0.433 & & & 0.249 \\
\hline Parents limit TV \& video games & -0.211 & & 0.134 & -0.038 & & & 0.071 \\
\hline \multicolumn{8}{|l|}{ Prior achievement } \\
\hline Grade 10 Mathematics & --- & --- & --- & 0.843 & $* * *$ & 0.822 & 0.009 \\
\hline Intercept & $47.155^{* * *}$ & & 0.801 & 49.761 & $* * *$ & & 0.371 \\
\hline \multicolumn{8}{|l|}{$\%$ of variance } \\
\hline at student level & 76.687 & & & 76.687 & & & \\
\hline explained at student level & 20.282 & & & 74.956 & & & \\
\hline explained by comp fun and gaming & 1.021 & & & 0.027 & & & \\
\hline
\end{tabular}

Note: $* p<0.05, * * p<0.01, * * * p<0.001$. Robust standard errors are reported.

Note: ${ }^{a}$ indicates variable is square root transformed.

Note: All continuous variables are grand mean centered.

Note: Models are weighted with normalized panel weights to adjust the estimates for the complex sampling procedure.

Note: The standardized beta coefficients can be interpreted as effect sizes.

\section{DISCUSSION}

This study is the first to test an independent direct effects model of student video gaming and using computers for fun on student achievement using a large nationally representative sample from the U.S. controlling for the multiple covariates of student achievement. In the debate over student use of technology for non-academic tasks that they deem as "gaming" or "fun", this study provides strong evidence that not only does this type of technology use not appear to be negatively associated with student achievement in high school, but our models show that the effects of using computers for fun and video gaming 1-2 hours a day are positive and significant on both cross-sectional reading and mathematics. However, this study provides no evidence to Bowers \& Berland (2013) Computer Use and Student Achievement support an assertion that using computers for fun and video gaming causes increased student achievement. Rather, this study provides evidence to inform current theories about the nuanced relationship between student recreational computer use and achievement as well as help shift the popular debate about computer use away from a paradigm that emphasizes its potential harm to one more attuned to the realities of student success.

The positive effect sizes of using computers for fun and gaming 1-2 hours a day on cross-sectional reading and mathematics standardized achievement scores, while small, are similar to student academic and school-related behaviors that schools routinely promote and endorse. These include homework outside of school, extracurricular activities, and reading outside of school, 
while controlling for the other variables in the models. The models presented here indicate this effect is independent and in addition to the associated influence of these other variables in the models. Thus, our findings support the assertion from the games and education literature domain that using computers for fun and moderate levels of video gaming may provide an additional avenue to improve student achievement in addition to other school activities such as homework, extracurricular activities, and recreational reading.

Nevertheless, while our findings are robust, both the exact meaning of uses computers for fun and the mechanism by which it is positively associated with student achievement remain obscure. The NCES survey question included in its definition of "for fun" such activities as talking to friends or relatives, emailing, playing games, surfing the internet, or listening to music. We argue that our inclusion of the gaming variable in addition to the using computers for fun variable helps to remove the confounding effects of gaming on using computers for fun. Thus, we posit that the construct represented by using computers for fun is in part a measurement of the amount of enjoyable student interaction with computers, and may represent an early effect of social networking in 2002 as well as engagement with text online. The results from this construct help to further inform the results from the research discussed above, such as Jackson et al. (2011) and Wittwer and Senkbeil (2008), that showed significant positive relationships between student achievement and "for fun" activities, such as uses of the internet, communicating with friends, and listening to music. Our results extend this previous research to a large nationally representative U.S. sample, with a comprehensive set of control variables, and identify positive significant effects for both reading and mathematics, effects which have not be clearly identified in the past research. However, Wittwer and Senkbeil's (2008) study demonstrated that this relationship appeared strongest for what they termed a "smart" gamer from their German sample, as they identified a typology of student computer use, indicating an interaction between different types of technology use and different types of student users. The focus of the present study was to build upon Wittwer and Senkbeil's (2008) central point that focused on "the way students use a computer at home... [rather than] ...whether, or how often, a computer is used" (p.1570). Their additional finding of different types of technology users is beyond the scope of this study, although we encourage future research to focus on examining the extent that their typology exists at the national level and examine the extent that different types of technology use are associated with student achievement.

In contrast, a growing research domain on the positive effects of gaming and student achievement indicates that students who regularly play video games may engage in creating and engaging with complex text and complex logic in important ways (Berland \& Lee, 2011; Gee, 2004; Steinkuehler \& Duncan, 2008). However, much of this past research has overly focused on small intact samples, qualitative descriptions, and a focus on specific games or gaming behaviors. Our study provides the first nationally generalizable evidence for the U.S. that moderate levels of gaming is positively associated with student achievement. Generalizing to all students who were in grade 10 in $2002,47 \%$ of the students reported playing video games one to two hours a day either weekdays or weekends - this equates to 1.478 million students. We posit that these same types of mechanisms that have been shown to enhance learning through gaming in the past small-scale studies are replicated here at the national level, and that while the effects appear to be small, they are significant and appear to be in addition to other well known positive covariates of student achievement both in and out of school.

For our final model, Model D, we found no difference in the effect sizes from grade 10 to grade 12 of using computers for fun, video gaming, and student mathematics achievement. We posit that this is most likely due to two issues around the specificity of the instrument. First, growth in standardized mathematics achievement is a narrowly defined outcome. The model tests for growth beyond that which was achieved by grade 10 . Our results demonstrate not that there was no effect on grade 12 students, but that there was no additional effect on grade 12 scores beyond that which is included within the grade 10 scores. In other words, neither computers for fun or video gaming appeared to influence the trajectory of the students, positive or negative, between grades 10 and 12. This is true of other variables as well, such as extracurricular activities. The effects appear to be embedded within the grade 10 mathematics score for Model D, and thus do not appear to add additionally to the model, in comparison to a variable like SES that continues to confer associated benefits to students by grade 12 beyond those gained by grade 10 . We have no data on other grade 12 outcomes such as reading, writing, science, or social studies performance, since NCES did not include those tests in the survey. It may be that recreational use of technology is significantly associated with growth in those outcomes. Second, we did find positive effects on cross-sectional reading and mathematics, which may indicate that, much like other variables that were significant in cross-sectional grade 12 mathematics but not on growth - such as non-traditional family, English as a first language, and Extracurricular activities (Model C), the association with achievement may occur at earlier grade levels but may not be related in the last two years of high school. Future work may explore these issues by including additional subject outcomes at earlier grade levels.

\section{Limitations and Directions}

Causality is difficult to ascertain. As just one example, our cause could be bias, in that students who were better at reading and mathematics in 2002 in high school were savvier at using a computer for fun. The broad interpretation of "for fun" in the survey question confounds causal conclusions, since the inclusion of "listening to music" may indicate a "Napster" effect in 2002, in that students who were downloading music "for fun" may be the same students who do better on standardized achievement tests in reading and mathematics. In addition, our moderate gamer variable captures only a narrow definition of video gaming in 2002, which has only become more expansive since the rise of social and online gaming communities (McGongial, 2011). With the design of this study, we are unable to speak to these issues with causality and the nuances of "for fun" and "moderate gaming" represented within each variable. In future research, we plan to explore the use of propensity score matching as well as randomized controlled experiments (Schneider, Carnoy, Kilpatrick, Schmidt, \& Shavelson, 2007), as two ways of exploring a causal connection between student recreational technology use and achievement.

In addition, our models included no variables at level 2 , the school level, since to date there is no theory that relates schoollevel effects to student recreational technology use. We included 
the school-level only to appropriately model the nested nature of students within schools, and address the well-known dependency issues with student and school data (Raudenbush \& Bryk, 2002). Nevertheless, the exclusion of school-level covariates may introduce bias in the models, especially if one wished to make inferences at the school level. One solution would be to use school-level aggregates of student-level variables at the schoollevel in the HLM analyses. However, because the NCES sampling procedure did not include all students in each school, but rather a small random sample, creating school-level averages would be problematic, and most likely would lead to additional bias in the models. Additionally, our focus here was on inference at the student level. Thus, school-level covariates are beyond the scope of this study.

Recent research on gaming and education has intimated that there may be a gender effect with technology and achievement (Gee \& Hayes, 2010). We originally set out in this study to test an interaction effect between gender, uses computers for fun, and video gaming (data not shown). However, these interactions created unacceptable levels of instability in the models. We encourage future work to examine how the effects of using computers for fun and video gaming on student achievement may be moderated by demographic variables, such as gender, ethnic background, and SES. If the recent small scale research holds true in larger more generalizable samples, then these types of student activities directed towards technology use for fun may be an attractive avenue to help address some of the known issues in historically disadvantaged student populations and contexts.

\section{RECOMMENDED CITATION FORMAT}

Bowers, A.J., Berland, M. (2013) Does Recreational Computer Use Affect High School Achievement? Educational Technology Research \& Development, 61(1), 51-69. doi:10.1007/s11423-012$\underline{9274-1}$

\section{REFERENCES}

APA. (2005). Resolution on Violence in Video Games and Interactive Media: American Psychological Association.

Anderson, C. A., Shibuya, A., Ihori, N., Swing, E. L., Bushman, B. J., Sakamoto, A., . . Saleem, M. (2010). Violent video game effects on aggression, empathy, and prosocial behavior in Eastern and Western countries: A meta-analytic review. Psychological Bulletin, 136(2), 151-173. doi: 10.1037/a0018251

Archibald, S. (2006). Narrowing in on educational resources that do affect student achievement. Peabody Journal of Education, 81(4), 23-42.

Berland, M., \& Lee, V. (2011). Collaborative strategic board games as a site for distributed computational thinking. International Journal of Game-Based Learning, 1(2), 65.

Borzekowski, D. L. G., \& Robinson, T. N. (2005). The remote, the mouse and the no. 2 pencil: The household media environment and academic acheivement among third grade students. Archives of Pediatrics and Adolescent Medicine, 159(7), 607-613.

boyd, d. (2008). Why youth (heart) social network sites: The role of networked publics in teenage social life. In D. Buckingham (Ed.), Youth, identity, and digital media (pp. 119-142). Cambridge, MA: MIT Press.

Bowers, A.J. (2009) Reconsidering Grades as Data for Decision Making: More than Just Academic Knowledge. Journal

Bowers \& Berland (2013) Computer Use and Student Achievement of Educational Administration, 47(5), 609-629. doi:10.1108/09578230910981080.

Bowers, A.J. (2011) What's in a Grade? The Multidimensional Nature of What Teacher Assigned Grades Assess in High School. Educational Research \& Evaluation, 17(3), 141-159. doi: 10.1080/13803611.2011.597112.

Brand-Gruwel, S., Wopereis, I., \& Vermetten, Y. (2005). Information problem solving by experts and novices: analysis of a complex cognitive skill. Computers and Human Behavior, 21(3), 487-508. doi: 10.1016/j.chb.2004.10.005

Collins, A., \& Halverson, R. R. (2009). Rethinking education in the age of technology : the digital revolution and schooling in America. New York: Teachers College.

Ferguson, C. J., \& Kilburn, J. (2010). Much ado about nothing: The misestimation and overinterpretation of violent video game effects in Eastern and Western nations: Comment on Anderson et al. (2010). Psychological Bulletin, 136(2), 174-178. doi: 10.1037/a0018566

Fuchs, T., \& Woessmann, L. (2004). Computers and student learning: Bivariate and multivariate evidence on the availability and use of computers at home and at school. CESifo Working Paper 1321. Munich: CESifo.

Gee, J. P. (2004). What video games have to teach us about learning and literacy: Palgrave MacMillan.

Gee, J. P., \& Hayes, E. R. (2010). Women and Gaming: The Sims and 21st Century Learning: Palgrave Macmillan.

Gentile, D. A., Lynch, P. J., Ruh Linder, J., \& Walsh, D. A. (2004). The effects of violent video game habits on adolescent hostility, aggressive behaviors, and school performance. Journal of Adolescence, 27, 5-22. doi: 10.1016/j.adolescence.2003.10.00

Graham, J. W., Cumsille, P. E., \& Elvira, E.-F. (2003). Methods for handling missing data. In I. B. Weiner, J. A. Schinka \& W. F. Velicer (Eds.), Handbook of psychology: Volume 2 Research methods in psychology. New York, NY: John Wiley \& Sons.

Hancox, R. J., Milne, B. J., \& Poulton, R. (2005). Association of television viewing during childhood with poor educational achievement. Archives of Pediatrics and Adolescent Medicine, 159(7), 614-618.

Huesmann, L. R. (2010). Nailing the coffin shut on doubts that violent video games stimulate aggression: Comment on Anderson et al. (2010). Psychological Bulletin, 136(2), 179-181. doi: 10.1037/a0018567

Hox, J. (2010). Multilevel analysis: Techniques and applications (Second ed.). New York: Routledge.

Ingles, S. J., Pratt, D. J., Rogers, J. E., Siegel, P. H., Stutts, E. S., \& Owings, J. A. (2004). Education longitudinal study of 2002: Base year data file user's manual. Washington, D.C.: National Center for Education Statistics, Institute of Education Sciences, U.S. Department of Education.

Ingles, S. J., Pratt, D. J., Wilson, D., Burns, L. J., Currivan, D., Rogers, J. E., \& Hubbard-Bednasz, S. (2007). Education longitudinal study of 2002: Base-year to second follow-up data file documentation. Washington, DC: National Center for Education Statistics, Institute of Education Sciences, U.S. Department of Education.

Jackson, L. A. (2008). Adolescents and the internet. In D. Romer \& P. Jamieson (Eds.), The changing portrayal of American youth in popular media, Annenberg public policy center at the University of Pennsylvania (pp. 377-410). NY: Oxford University Press. 
Jackson, L. A., von Eye, A., Biocca, F. A., Barbatsis, G., Zhao, Y., \& Fitzgerald, H. E. (2006). Does home internet use influence the academic performance of low-income children? Developmental Psychology, 42(3), 429-435. doi: 10.1037/0012-1649.42.3.429

Jackson, L. A., von Eye, A., Witt, E. A., Zhao, Y., \& Fitzgerald, H. E. (2011). A longitudinal study of the effects of Internet use and videogame playing on academic performance and the roles of gender, race and income in these relationships. Computers in Human Behavior, 27(1), 228-239. doi: 10.1016/j.chb.2010.08.001

Jenkins, H. (2006). Fans, bloggers, and gamers: Exploring participatory culture: NYU Press.

Jonassen, D. H., \& Kwon, H. (2001). Communication patterns in computer mediated versus face-to-face group problem solving. Educational Technology Research and Development, 49(1), 35-51. doi: 10.1007/BF02504505

Keith, T. Z., Reimers, T. M., Fehrmann, P. G., Pottebaum, S. M., \& Aubey, L. W. (1986). Parental involvement, homework, and TV time: Direct and indirect effects on high school achievement. Journal of Educational Psychology, 78(5), 373

Klein, S. (2010). Study: Too Many Video Games May Sap Attention Span - Health News - Health.com. Retrieved from http://news.health.com/2010/07/05/video-gamesattention-span/

Kuncel, N. R., Crede, M., \& Thomas, L. L. (2005). The validity of self-reported grade point averages, class ranks, and test scores: A meta-analysis and review of the literature. Review of Educational Research, 75(1), 63-83.

Lewis, C., \& Fabos, B. (2005). Instant messaging, literacies, and social identities. Reading Research Quarterly, 40(4), 470-501.

McGonigal, J. (2011). Reality is broken: Why games make us better and how they can change the world. New York: The Penguin Press.

Nævdal, F. (2007). Home-PC usage and achievement in English. Computers \& Education, 49(4), 1112-1121. doi: 10.1016/j.compedu.2006.01.003

NCES. (n.d.). Education longitudinal study of 2002 (ELS:2002), from http://www.nces.ed.gov/surveys/els2002/

OECD. (2006). Are students ready for a technology-rich world? What PISA studies tell us. Paris: OECD.

Papanastasiou, E. C., Zembylas, M., \& Vrasidas, C. (2003). Can computer use hurt science achievement? The USA results from PISA. Journal of Science Education and Technology, 12(3), 325-332. doi: 10.1023/A:1025093225753

Papert, S. (1980). Mindstorms: children, computers, and powerful ideas. NYC: Basic Books.

Pew. (2000). Tracking online life: How women use the internet to cultiavate relationships with family and friends.

Retrieved from http://www.pewinternet.org/Reports/2000/TrackingOnline-Life

Pew. (2005). Digitial divisions. Retrieved from http://www.pewinternet.org/Reports/2005/DigitalDivisions.aspx

Pew. (2006). Internet evolution, internet penetration and impact. Retrieved from http://www.pewinternet.org/Reports/2006/InternetPenetration-and-Impact.aspx
Raudenbush, S. W., \& Bryk, A. S. (2002). Hierarchical linear models: Applications and data analysis methods (2nd ed.). Thousand Oaks: Sage.

Raudenbush, S. W., Bryk, A. S., Cheong, Y. F., Congdon, R., \& duToit, M. (2011). HLM 7: Hierarchical linear and nonlinear modeling. Lincolnwood, IL: Scientific Software International, Inc.

Rumberger, R. W., \& Palardy, G. J. (2005). Test scores, dropout rates, and transfer rates as alternative indicators of high school performance. American Educational Research Journal, 42(1), 3-42.

Schneider, B., Carnoy, M., Kilpatrick, J., Schmidt, W. H., \& Shavelson, R. J. (2007). Estimating casual effects: Using experimental and observational designs (report from the Governing Board of the American Educational Research Association Grants Program). Washington, DC: American Educational Research Association.

Southwell, B. G., \& Doyle, K. O. (2004). The Good, the Bad, or the Ugly? American Behavioral Scientist, 48(4), 391401. doi: $10.1177 / 0002764204270277$

SPSS. (2010). SPSS Inc. (Version 19.0): IBM SPSS Inc.

Steinkuehler, C., \& Duncan, S. (2008). Scientific habits of mind in virtual worlds. Journal of Science Education and Technology, 17(6), 530-543. doi: 10.1007/s10956-0089120-8

Strayhorn, T. L. (2009). Acessing and analyzing national databases. In T. J. Kowalski \& T. J. Lasley (Eds.), Handbook of data-based decision making in education (pp. 105-122). New York, NY: Routledge.

Subrahmanyam, K., Greenfield, P., Kraut, R., \& Gross, E. (2001). The impact of computer use on children's and adolescents' development. Journal of Applied Developmental Psychology, 22(1), 7-30.

Sutherland, R., Facer, K., Furlong, R., \& Furlong, J. (2000). A new environment for education? The computer in the home. Computers \& Education, 34(3-4), 195-212. doi: 10.1016/S0360-1315(99)00045-7

Tabatabai, D., \& Shore, B. M. (2005). How experts and novices search the web. Library \& Information Science Research, 27(2), 222-248. doi: 10.1016/j.lisr.2005.01.005

Turkle, S. (1995). Life on the screen: Identity in the age of the internet. New York: Simon \& Schuster.

Turkle, S. (2011). Alone together: Why we expect more from technology and less from each other. New York: Basic Books.

Van den Bulck, J. (2004). Television viewing, computer game playing, and Internet use and self-reported time to bed and time out of bed in secondary-school children. Sleep, 27(1), 101-104.

Willoughby, T. (2008). A short-term longitudinal study of Internet and computer game use by adolescent boys and girls: Prevalence, frequency of use, and psychosocial predictors. Developmental Psychology, 44(1), 195-204. doi: 10.1037/0012-1649.44.1.195

Wittwer, J., \& Senkbeil, M. (2008). Is students' computer use at home related to their mathematical performance at school? Computers \& Education, 50(4), 1558-1571. doi: doi:10.1016/j.compedu.2007.03.001 